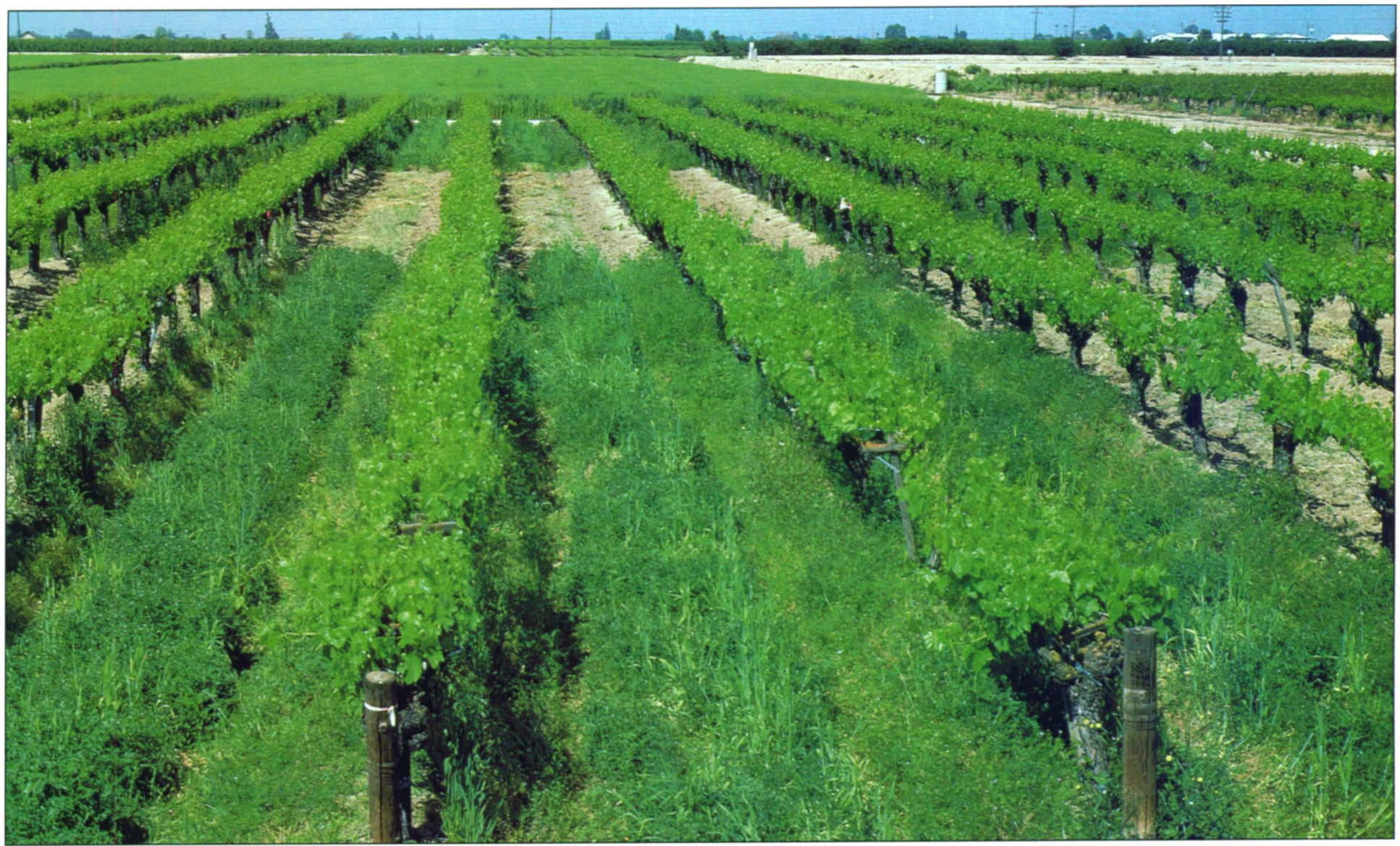

In both experimental and commercial vineyards, scientists examined the effects of cover crops on the numbers of leafhopper pests and beneficial insects.

\title{
Can cover crops reduce leafhopper abundance in vineyards?
}

Kent M. Daane a Michael J. Costello

In 3 of 4 vineyards we studied, late-season leafhopper density was lower on vines in cover cropped plots than in plots with no cover crops. However, the level of leafhopper'reduction (about 15\%) was rarely economically important and the mechanisms leading to reduction were not clear. For example, there were few differences in the number of leafhopper predators or parasitoids on the vines in cover cropped versus no cover plots. However, there were significant between-treatment differences in vine growth. Plots with seasonwide maintenance of a cover crop and resident grasses had a reduction in vine vigor. Lower vine vigor has been associated with lower leafhopper densities and, in our studies conducted from 1993 to 1996 , those plots with reduced vine vigor often had the greatest reduction in late-season leafhopper density.
Cover crops have been used to attract beneficial insects that will potentially suppress pest populations. Indeed, many grape growers are managing floor vegetation as one component of their integrated pest management (IPM) program (Mayse et al. 1995; Costello and Daane 1998c), and some growers and researchers have observed lower leafhopper numbers after the addition of a cover crop to some vineyards. Still, the role of cover crops in vineyard IPM is not well understood, and their use to help manage leafhoppers 


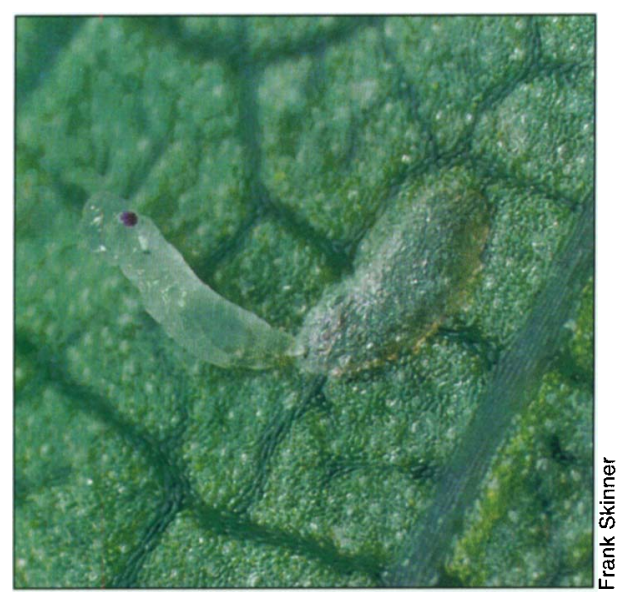

The first instar grape leafhopper emerging from its egg. Studies indicate that these small leafhopper stages are sensitive to vine conditions, such as water stress, which can be influenced by the presence of perennial cover cropping systems.

and other vineyard pests is a controversial practice.

How might the addition of a cover crop lead to lower leafhopper abundance? The benefits of increased plant diversity for pest management have long been debated. In a number of cropping systems, researchers showed that natural enemy densities increase in more diverse cropping systems because the added vegetation provides additional habitat and/or food (Andow 1991; Bugg and Waddington 1994). Alternate food can be other prey species (e.g., aphids on the cover crop) or food for adult predators or parasitoids (e.g., pollen, nectar and honeydew). While cover cropping is the most common method to increase plant diversity in vineyards, there are relatively few scientific studies that have documented its role in vineyard IPM.

Here, we summarize experiments, conducted from 1993 to 1996, that sought to determine the relationship between cover cropping, leafhopper numbers, abundance and species composition of spiders, parasitism by Anagrus species, and changes in vine condition.

Two leafhopper species are important vineyard pests: the western grape leafhopper, Erythroneura elegantula, and the variegated leafhopper, Erythroneura variabilis (Wilson et al. 1992a, 1992b). Feeding by leafhopper adults and nymphs damages leaf tissue, which decreases photosynthesis and can lead to defoliation. As leafhoppers feed, they produce honeydew, which acts as a substrate for sooty molds that reduce the quality of grapes. Additionally, adult leafhoppers, flying at harvest, can hinder vineyard workers.

We used spiders to compare relative differences between generalist predator populations in cover crop and in no cover treatments for several reasons. First, the vast majority of leafhopper predators on the vines are spiders (Costello and Daane 1998b). Second, exclusion experiments have shown that spiders can affect leafhopper abundance (Zalom et al. 1993). Third, cover crops can influence spider species composition (Costello and Daane 1998a) and might help to increase spider numbers by providing habitat and alternate food sources (insects and mites on the cover crop are potential prey).

The most important leafhopper parasitoids are Anagrus erythroneurae and Anagrus daanei, which were formerly grouped together as Anagrus epos (Triapitsyn 1998). Female Anagrus lay a single egg into a leafhopper egg, where the parasitoid completes its entire egg, larval and pupal development periods, emerging from the leafhopper egg as an adult parasitoid. These tiny wasps can barely be seen without a microscope, yet they are found in all vineyards and by the end of the season they outnumber all other leafhopper natural enemies. Anagrus spp. can effectively reduce western grape leafhopper densities; however, they do not provide good control of the variegated leafhopper (Settle et al. 1986; Pickett et al. 1987). In theory, cover crops can provide alternate food for adult Anagrus spp. that feed on carbohydrate sources (e.g., sugars in plant nectar).

Leafhoppers prefer vigorously growing vines (Trichilo et al. 1990). When this relationship was experimentally tested, excess irrigation correlated with higher leafhopper nymph and adult densities, larger leafhopper size and more leafhopper eggs depos- ited on leaves (Daane et al. 1995). Because some cover crops can compete with vines for water and nutrients they can affect vine vigor (Wolpert et al. 1993).

\section{Study sites}

We conducted studies at four different sites in the San Joaquin Valley. Three of the sites were at commercial vineyards (table, raisin and wine grapes), where plot sizes were large; one site was at a UC experiment station (juice grapes), where plot size was relatively small. No insecticides were applied for leafhopper control during the study. The raisin vineyard was treated with propargite (Omite) in late May 1994 for spider mite control, which lowered the density of the first leafhopper generation.

Juice grape site. In a juice grape vineyard (cv Thompson Seedless) at the UC Kearney Agricultural Center in Parlier, we tested two treatments: (1) no cover crop and (2) cover crop and resident vegetation present all season. The no cover crop plots were established by disking under all ground vegetation in March and maintained by disking every month thereafter. In fall 1992 and 1993, the cover crop plots were seeded with a $4: 1$ mixture of purple vetch (Vicia benghalensis) and barley (Hordeum oulgare) at $25 \mathrm{lb} / \mathrm{ac}$ (25 kg/ha). To maintain the cover crop plots, the in-row ground vegetation was mowed periodically; however, no weed control was used on the berms directly under the vines. As the seeded cover crop dried down during the summer, it was naturally replaced by a mixture of resident grasses, which included cupgrass (Eriochloa gracilis), large crabgrass (Digitaria sanguinalis), and yellow foxtail (Setaria gracilis). The treatments were set in a randomized complete block design, with six replicates. Plots were 0.11 acre each $(0.05$ ha, 4 rows $\times 13$ vines). Data were collected from May to September in 1993 and 1994.

Table grape site. In a table grape vineyard (cv Ruby Seedless) near Reedley, two treatments were tested: (1) no cover crop and (2) cover crop and/or resident vegetation present all 
season. The no cover crop plots were established by tilling under all ground vegetation in March, and maintained free of vegetation by either applying multiple glyphosate sprays (1993) or by cultivating the middles between the rows and French plowing the berms directly under the vines (1994 and 1995). In November 1992 and 1993, the cover crop plots were seeded with a 4:1 mixture of purple vetch (Vicia benghalensis) and barley (Hordeum vulgare) at $25 \mathrm{lb} / \mathrm{ac}(25 \mathrm{~kg} / \mathrm{ha})$. In November 1994, the site was seeded to a 1:1:1 mixture of fava beans (Vicia fava), Austrian winter peas (Pisum sativum) and common vetch (Vicia sativa) at 50 $\mathrm{lb} / \mathrm{ac}(50 \mathrm{~kg} / \mathrm{ha})$. The cover crop plots were mowed in March, allowed to regrow, mature and set seed. After the sown cover crop went to seed, it was naturally replaced by resident grasses, which included cupgrass, large crabgrass, yellow foxtail and knotweed (Polygonum aviculare). The treatments were set in a randomized complete block design, with five replicates. Plots were 1.4 acres each $(0.56$ ha, 8 rows $x$ 80 vines). Data were collected from May to October, 1993 to 1995.

Wine grape site. In a wine grape vineyard (cv Cabernet Sauvignon) in Woodbridge, we tested two treatments: (1) no cover crop and (2) cover crop of perennial grasses that are native to California. The no cover plots were maintained by tilling under all ground vegetation in March and every two weeks thereafter. In fall 1993, the cover crop plots were seeded with a 1:1:1 native grass mixture of blue wildrye (Elymus glaucus), meadow barley (Hordeum brachyantherum) and California brome (Bromus carinatus), at a rate of $25 \mathrm{lb} / \mathrm{ac}(25 \mathrm{~kg} / \mathrm{ha})$. The cover crop was mowed when needed and in-row weed control was accomplished by mechanical cultivation. The treatments were set in a randomized complete block design, with four replicates. Plots were 1.1 acres each $(0.4$ ha, 6 rows $x 90$ vines). Data were collected from May to October, 1994 to 1996.

Raisin grape site. We used a raisin grape vineyard (cv Thompson Seedless) near Del Rey to test the benefits of a cover crop maintained for only a

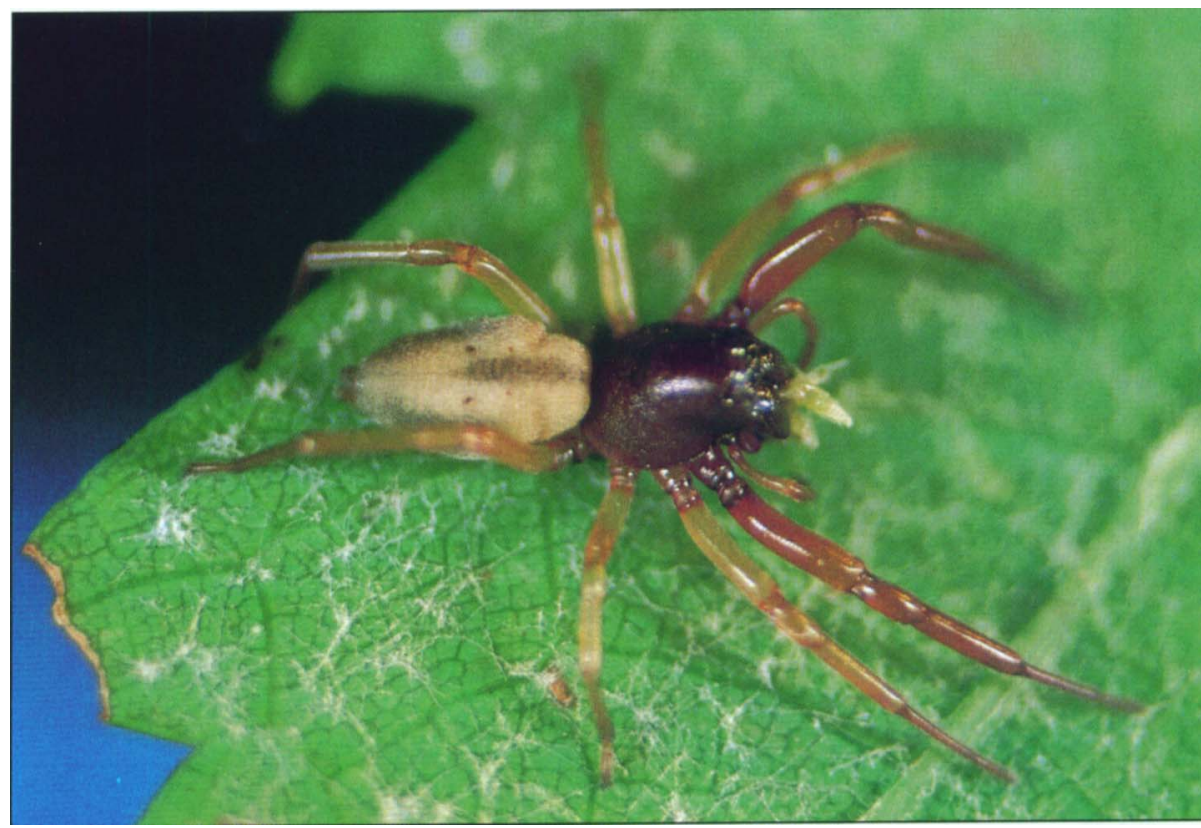

Trachelas pacificus, shown above, eats about 12 leafhoppers per day. In comparison, cobweb weavers eat only 1 or 2 leafhoppers per day. Scientists found few differences on the vine in spider density or species composition in plots with or without cover crops.

part of the growing season. Because raisins are typically dried on the ground, there must be a period near harvest without cover crop. We tested two treatments: (1) no cover crop and (2) cover crop present through June.

The no cover plots and in-row weeds in the cover crop plots were treated in February of each year with $1.5 \mathrm{lb} / \mathrm{ac}$ $(1.5 \mathrm{~kg} / \mathrm{ha})$ each of simazine and oxyfluorfen. To establish the cover crop plots, in November 1993 and 1994, a 4:1 mixture of purple vetch (Vicia benghalensis) and barley (Hordeum vulgare) was seeded at $11 \mathrm{lb} / \mathrm{ac}$ $(11 \mathrm{~kg} / \mathrm{ha})$. The cover crop was mowed periodically, until early July, when it was disked under to prepare the vineyard floor for harvest. The experiment was established in a randomized complete block design, with four replicates. Plots were 1.5 acres each (0.6 ha, 8 rows $x 100$ vines). We collected data from May to October, 1994 and 1995.

\section{Sampling methods}

At all sites, we sampled for leafhoppers, spiders and Anagrus spp. Leaf nitrogen status and cane growth were used to estimate vine vigor.

Leafhoppers. We counted nymphs on 20 or 30 leaves per plot, with samples taken near the peak density of each leafhopper generation. In the San
Joaquin Valley, leafhopper generations peak in late May to early June (first generation), mid-to-late July (second generation) and early September (third generation). Sampled leaves were selected from the middle row(s) of each plot and on leaf nodes 1 to 3,4 to 6 and 5 to 10 in the first, second and third leafhopper generations, respectively, to follow leafhopper density patterns (Wilson et al. 1992a, 1992b).

Spiders. We sampled spiders using methods described by Costello and Daane $(1995,1997)$. Samples were taken each month from May to September. At the juice and table grape sites, spiders on the vines were sampled by laying a 10 -foot-by-24-foot $(3 \mathrm{~m} \times 7.3 \mathrm{~m}$ ) muslin sheet on the ground directly beneath the area covered by the trunk, canes and foliage of two adjacent vines. For about $15 \mathrm{sec}-$ onds, the vine foliage and trunk were shaken to dislodge predators onto the muslin sheet. Except for phytoseiid mites, all ambulatory predators were collected. At the wine and raisin grape sites, predators were sampled with a cloth funnel that had a 2.8-foot-by-2.8foot $(0.9 \mathrm{~m} \times 0.9 \mathrm{~m})$ PVC frame at the top and tapered to 0.3 -foot-by-0.3-ft $(0.1 \mathrm{~m} \times 0.1 \mathrm{~m})$ at the bottom. The funnel was held under a section of foliage between two vines, and the vines were shaken for about 15 seconds to dis- 


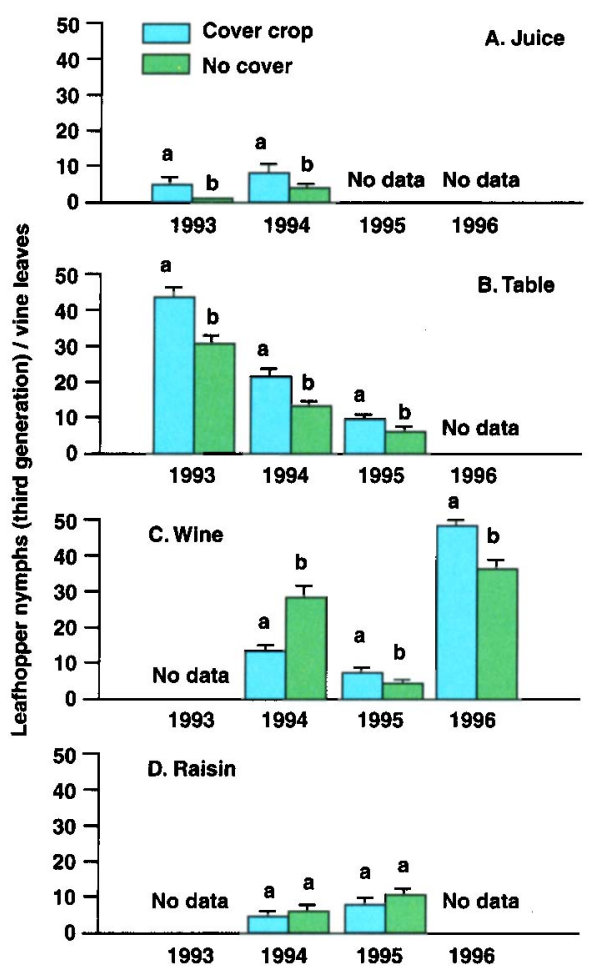

Fig. 1. Mean third-generation leafhopper nymph counts ( \pm SEM) show lower pest densities in cover crop than no cover treatments in (A) juice grapes - 1993, 1994; (B) table grapes - 1993, 1994, 1995; and (C) wine grapes $-1995,1996$. There was no between-treatment difference at the (D) raisin grape site. In each year and vineyard, paired means followed by different letters are significantly different (Tukey HSD test, $P<0.05$ ). Data from the wine grape site in 1994 are from the second generation because severe defoliation in the third generation resulted in lower leafhopper densities.

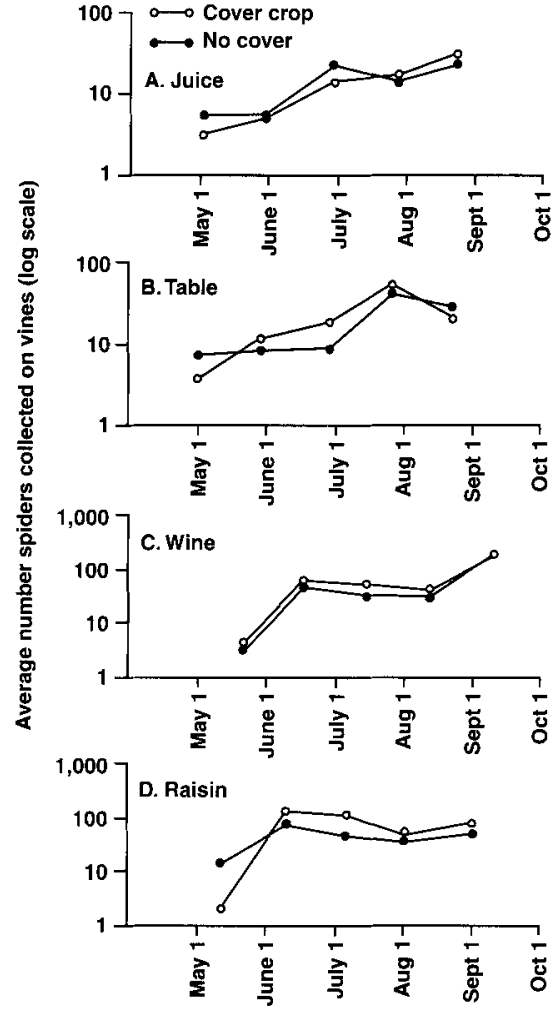

Fig. 2. Monthly mean spider densities in the four vineyard study sites, with cover crop and no cover plots. Repeated Measures Analysis of Variance found no significant difference in total spider abundance at sites in (A) juice grapes $(P=$ $0.639)$, (B) table grapes $(P=0.606)$ and $(C)$ wine grapes $(P=0.318)$. There was a significant $77 \%$ increase in total spider abundance at the (D) raisin grape site $(P=$ 0.001 ). Data from one year, 1994, are presented from each of the four vineyards studied.

lodge spiders into a collection bag at the bottom of the funnel.

We sampled spiders on the cover crop by placing a 3-foot-by-5-foot ( 0.9 $\mathrm{m} \times 1.5 \mathrm{~m}$ ) frame on two randomly selected sections of ground cover in each plot. Spiders within the frame boundaries were collected with a D-vac. For both vine and cover crop, we recorded the number and species of spiders collected and transformed data to "spiders per vine" based on the sample area (Costello and Daane 1997). Because there are behavioral and ecological differences among spider species, spider abundance and species composition can vary dramatically among vineyards (Costello and Daane 1995).
For this reason, we analyzed the spider community by individual species and as a whole.

Egg parasitoids. We determined percentage egg parasitism by examining 20 leaves sampled from vines in the middle row(s) of each plot. The leaves were collected from leaf nodes 2 to 3,5 to 7 and 7 to 10 at the end of the first, second and third leafhopper generations, respectively (Wilson et al. 1992a, 1992b). We viewed collected leaves through a dissecting microscope and recorded the number of hatched and parasitized (parasitoid emergence hole) eggs.

Vine vigor. Leaf nitrogen status can indicate vine vigor (Kliewer et al.
1991) and was measured by petiole samples collected from 30 randomly selected vines per plot ( 1 to 3 petioles per vine). Petioles were dried, ground and sent to the UC DANR Analytical Laboratory and nitrate $\left(\mathrm{NO}_{3}\right)$ levels determined. Another measure of vine vigor is cane pruning weight (Wolpert et al. 1993). Two vines per plot were pruned in the winter and the canes weighed.

\section{Leafhopper density lowered}

Leafhoppers. The presence of a cover crop did not result in lower densities of leafhopper nymphs in the first generation. At only one site (wine grape) were nymph densities lower in the second generation. Because leafhopper density is often greater later in the season, the third leafhopper generation can be the more crucial period for economic damage. Third-generation nymph densities were significantly lower in cover crop plots in all years at the juice and table grape sites (figs. 1A, $1 B$ ) and in 2 of 3 years at the wine grape site (fig. $1 \mathrm{C}$ ). In the raisin vineyard, where the cover crop was disked under in July to prepare for harvest, there were no significant differences in leafhopper densities between treatments (fig. 1D). For all sites and years combined, the average reduction of thirdgeneration leafhopper density was about $15 \%$, but in only one case did this reduce leafhopper numbers below the acceptable level of about 15 to 20 nymphs per leaf (fig. 1B-1994). In other years, leafhopper densities were so low (e.g., fig. 1B-1995) or so high (e.g., fig. 1B-1993) that the addition of cover crops and the resultant reduction in leafhopper numbers did not make a practical change.

\section{What reduced leafhopper numbers?}

What mechanisms could have resulted in lower leafhopper densities in cover crop plots? We discuss three possibilities: (1) a change in spider numbers or species composition, (2) an increase in parasitoid numbers, or (3) a change in vine condition.

Spiders. Can the addition of a cover crop affect spiders to help reduce leafhopper pest problems? One possibility is that there are more spiders on vines in the cover crop plots. In this study, 


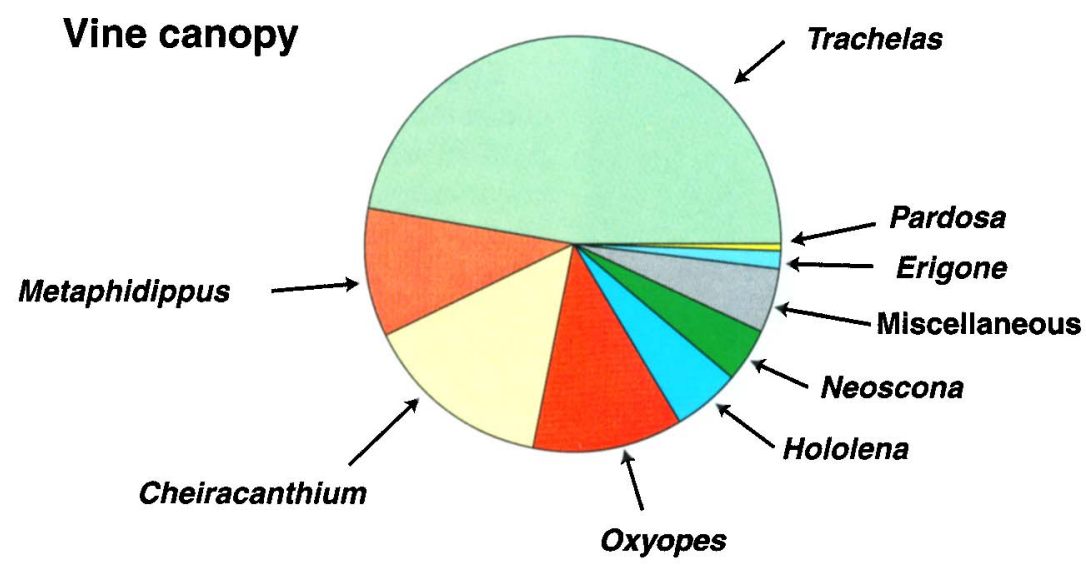

Cover crop

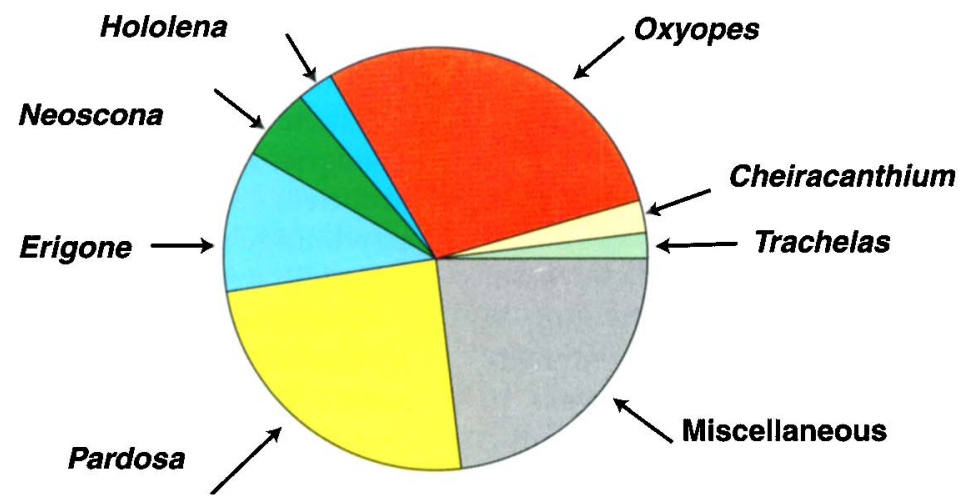

Fig. 3. Spider species composition in a table grape vineyard (1993 to 1995) shows wide differences between spider species on the vine and those on the cover crop.
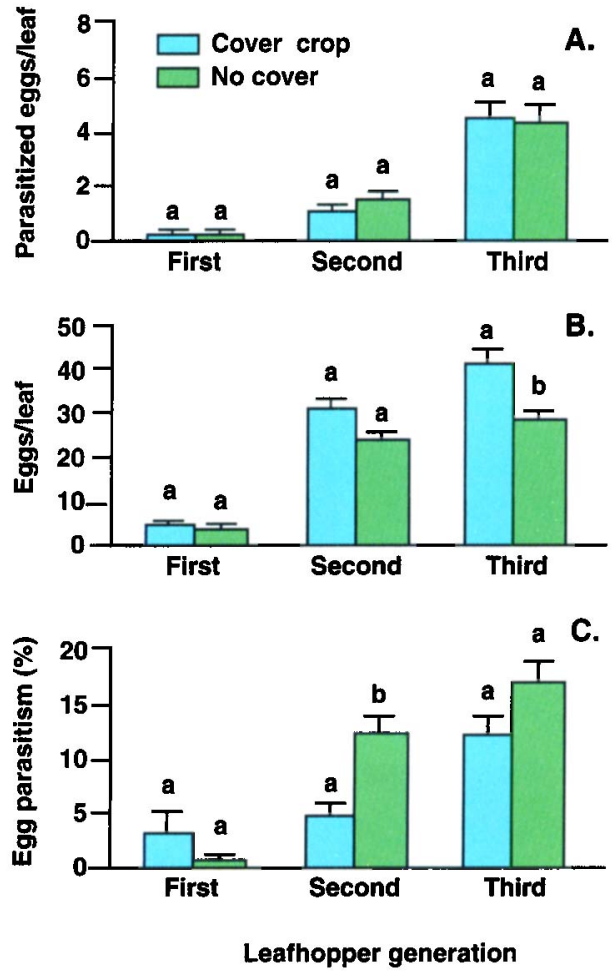

Fig. 4. In a wine grape vineyard in 1996: (A) Mean ( \pm SEM) parasitized eggs, (B) total eggs and $(C)$ percentage egg parasitism of variegated leafhopper. Although the number of parasitized eggs did not differ between treatments, total leafhopper egg numbers were significantly lower in the cover crop treatment, which may have resulted in a higher percentage parasitism. In each grouping, means followed by different letters are significantly different (Tukey HSD test, $P<0.05$ ). however, we found that total spider abundance on the vines was not significantly different between cover and no cover treatments in the juice, table and wine grape sites (figs. 2A, 2B and 2C; data are shown from 1994 and accurately represent data collected in each trial because there was not a sig nificant year $x$ treatment interaction). Only at the raisin grape site was total spider abundance on vines significantly higher in cover crop plots as compared with the no cover plots (fig. 2D) and at the raisin site there were no between-treatment differences in leafhopper densities in any trial. Therefore, in 3 of 4 vineyards ( 8 of 10 annual trials) the addition of a cover crop did not significantly increase the total number of spiders on the vines.

Of course, overall spider abundance in the vineyard (vines and cover crop) was higher in cover crop plots because many spiders live on the cover crop. Can the spiders residing on the cover crop help to lower leafhopper densities? One possibility is that spiders migrate between the cover crop and the vines. The great difference in spider species composition between the cover crop and vines (fig. 3); however, suggests that there is not a large-scale migration between these two habitats. We conclude that the cover crop did not provide an important alternate habitat for vine-dwelling spiders in our studies. More likely, winged insects move between the cover crop and vines. We have observed mobile insects that feed on the cover crop, such as winged aphids, fly onto the vines where they are killed by resident spiders. These alternative prey items may help support spiders that reside year-round on the vines, especially during periods when leafhoppers are not abundant. Similarly, adult leafhoppers often fly down to the cover crop, where they may fall prey to spiders.

A third possibility is that the cover crop influenced the types or proportions of individual spider species on the vines. Spider species composition is important because each species may impact pest populations differently. For example, in laboratory studies, Trachelas pacificus ate about 12 leafhoppers per day while, in comparison, cobweb weavers killed only 1 to 2 leafhoppers per day. Did the addition of a cover crop change the spider species composition on the vines? In this study, the more common spiders collected on the vines included the large nocturnal hunters (Trachelas pacificus and Cheiracanthium inclusum), lynx spi- 


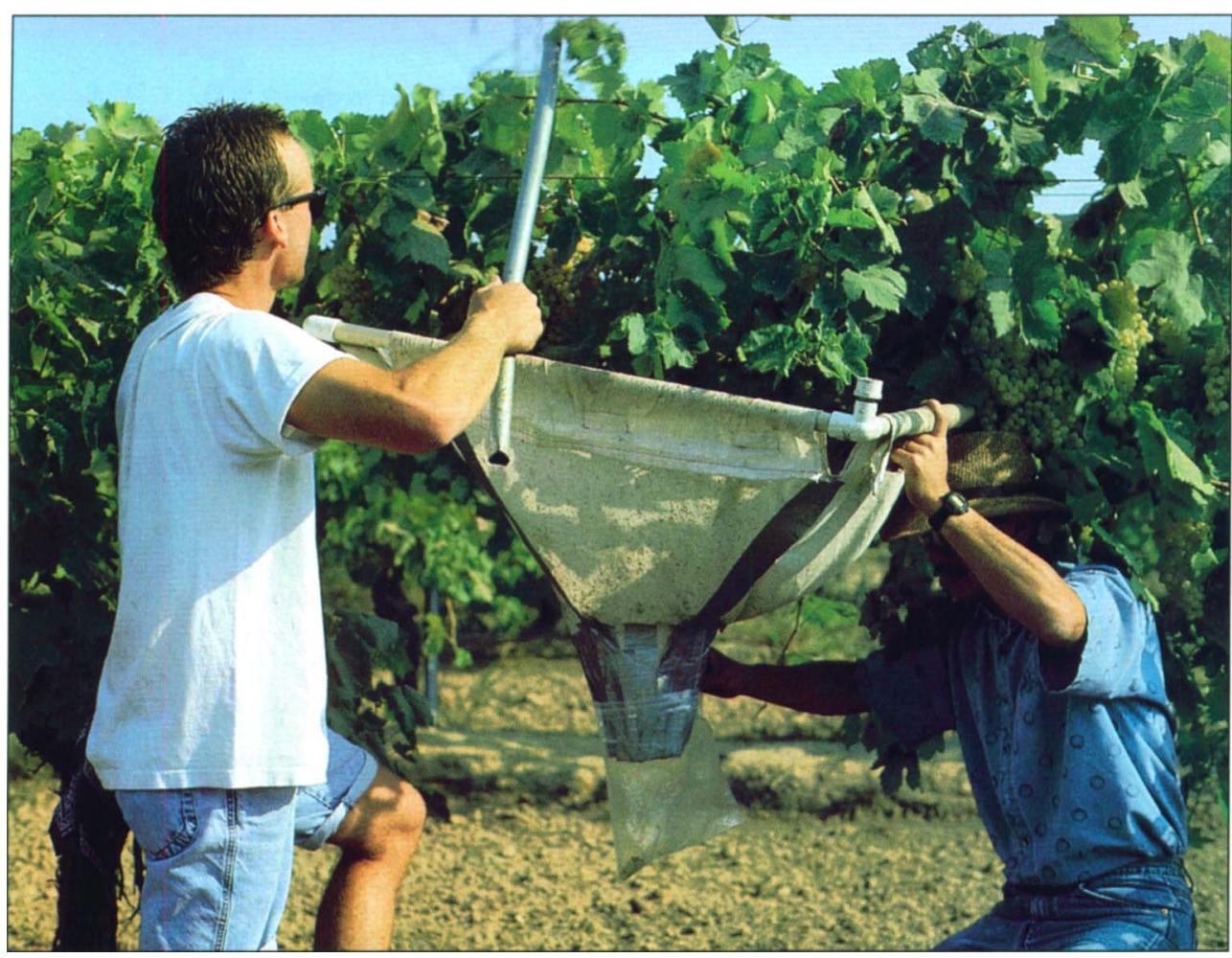

At the wine and raisin vineyards studied, spiders were sampled by shaking foliage over a cloth funnel.

ders (Oxyopes scalaris and O. salticus), small cobweb weavers (Theridion dilutum and T. melanurum), a funnel weaver (Hololena nedra) and a jumping spider (Metaphidippus vitis). The proportions (or species composition) of these spider species were similar between cover crop and no cover plots at 2 of 4 sites. The two exceptions were the table grape site and the raisin site. At the table grape site, late season densities of one spider species,

Trachelas pacificus, were $40 \%, 84 \%$ and $80 \%$ higher in cover crop than no cover plots in 1993, 1994 and 1995 study years, respectively $(P=0.017$,
Tukey HSD test, all years combined). At the raisin site, $T$. pacificus was higher in cover crop than no cover plots in 1993 and 1994 ( $P=0.026$, Tukey HSD test, all years combined). The results suggest that the spider community in a vineyard cannot be easily manipulated simply through the presence or absence of cover crops. Besides cover cropping, factors such as vine cultivar, regional climate, vineyard microclimate, vineyard age, prey species composition and management practices all influence predator species composition (Costello and Daane 1995, 1998a).

TABLE 1. Mean ( \pm SEM) vine growth and nutrition parameters from vineyards with and without ground covers, data are presented from a single year of study for each vineyard site

\begin{tabular}{lllcc}
\hline \hline $\begin{array}{l}\text { Vine health } \\
\text { parameter }\end{array}$ & $\begin{array}{c}\text { Study } \\
\text { site }\end{array}$ & Year & \multicolumn{2}{c}{ Treatment } \\
\cline { 4 - 5 } Pruning weight $(\mathrm{g})$ & Cover crop & No cover \\
& Table & 1994 & $2.7(0.1)$ & $3.4(0.2)^{*}$ \\
& Raisin & 1994 & no data & no data \\
& Wine & 1994 & $4.5(0.6)$ & $6.0(0.5)^{*}$ \\
Petiole nitrate & Juice & 1994 & $2.7(0.4)$ & $5.3(0.7)^{*}$ \\
& Table & 1995 & $28.0(4.9)$ & $142.0(36.0)^{*}$ \\
& Raisin & 1995 & $585.0(108.0)$ & $500.0(112.0) \mathrm{ns}$ \\
& Wine & 1996 & $301.2(236.7)$ & $1,783.5(388.5)^{*}$ \\
& Juice & 1994 & $90.0(38.5)$ & $405.0(92.6)^{*}$ \\
\hline
\end{tabular}

*The difference between means is significant at $\mathrm{P}<0.05$ (Tukey HSD test), ns = not significant.

Egg parasitism. There were no consistent differences in the number of parasitized leafhopper eggs between cover crop and no cover treatments at any of the studied vineyards. On occasion, we found that the percentage of eggs parasitized was greater in cover crop plots; however, this difference could not be easily explained by any single factor, such as an increase in Anagrus numbers. This is illustrated by data from the wine grape site, where there was no difference in the number of parasitized eggs between treatments (fig. 4A), but the total number of leafhopper eggs was lower on vines in cover crop plots (fig. 4B), perhaps because of lower vine vigor. Because adult Anagrus had fewer host eggs to parasitize in cover crop plots, the same number of Anagrus (assuming equal fecundity and searching abilities) could result in the higher percentage parasitism observed (fig. 4C).

This does not dispute the possibility that a cover crop can provide alternative food sources for parasitoids (e.g., nectar). Leafhoppers and other vine-dwelling insects produce small droplets of honeydew, and this sugary liquid may provide the needed carbohydrates for adult Anagrus. In fact, laboratory observations show that Anagrus can use a carbohydrate source for increased adult longevity. This carbohydrate source on the vines would reduce the parasitoids' need to search for a supplemental food source in the cover crop. Another possibility is that there are alternative leafhopper host species on the cover crop for Anagrus to attack. While there are other leafhopper species found on cover crops, no evidence has been found (or formal studies conducted) to indicate that eggs of these leafhoppers can serve as hosts for Anagrus spp. that attack grape leafhoppers or variegated leafhoppers.

Vine vigor. At 3 of 4 sites (table, wine and juice) the addition of a cover crop affected vine condition, as indicated by significantly lower pruning weights and petiole nitrate levels (table 1). At these same sites there was a reduction in leafhoppers in all but 
one year (fig. 1). At the raisin site, where cover crops were tilled under by midseason, there was no measurable vine stress (table 1 ) or difference in leafhopper numbers between cover crop and no cover treatments (fig. 1D). These data suggest that the reduction in vine vigor contributed to the reduction in leafhopper numbers. As mentioned, researchers have previously shown that some cover crops can compete with vines for water and/or nutrients, thereby reducing vine vigor (Wolpert et al. 1993) and that reduced vine vigor (Wilson et al. 1992a) or irrigation amounts (Trichilo et al. 1990, Daane et al. 1995) can result in lower leafhopper densities.

\section{Conclusions}

In our studies, cover crops maintained throughout the year (juice, table and wine grape sites) resulted in lower third-generation leafhopper densities in 7 of 8 trials, as compared with the no cover treatment. Just as important, the level of leafhopper reduction was commonly less than $20 \%$, which was often not economically significant. Leafhopper reduction could not be clearly attributed to any single factor. There were relatively few differences in spider density or spider species composition on vines in cover crop and no cover treatments. Similarly, there were no consistent differences in the number of leafhopper eggs parasitized by Anagrus spp. on vines in cover crop and no cover treatments. The most commonly observed trait among plots with lower leafhopper densities was not a biotic change but an abiotic one: cover crops and resident vegetation that was maintained all year also showed a reduction in vine vigor. In comparison, at the raisin grape site, the cover crop was disked under in summer, and there was neither a reduction in leafhopper numbers nor vine vigor. The results corroborate earlier research that showed lowered vine vigor could occur after the addition of some species of perennial cover crops, with lower leafhopper densities on the less vigorous vines.

We note that manipulating vine condition for leafhopper control may be a double-edged sword. Whereas vigorously growing vines tend to have more leafhoppers, they can withstand higher leafhopper densities with less economic damage. Conversely, while poorly growing vines tend to have fewer leafhoppers, low leafhopper densities can cause greater economic damage on poorly growing vines. Also, because the vineyard ecosystem is complex, many factors combine to influence both pest and natural enemy densities (e.g., vineyard cultural practices, vineyard age, soil characteristics and regional characteristics). Therefore, the effects of cover cropping on pest or natural enemy numbers may vary between vineyards. Overall, our studies show that cover crops and other floor vegetation can play a role in vineyard pest management, but they cannot be relied upon to provide complete control of leafhoppers. Properly managed cover crops should be considered only a part of an overall IPM program.

K.M. Daane is Associate Specialist, Center for Biological Control, Division of Insect Biology (Dept. ESPM), UC Berkeley, stationed at the Kearney Agricultural Center, Parlier; and M.J. Costello is Farm Advisor, UC Cooperative Extension, Fresno County. The authors thank the Mondavi Winery, the Smeds' Savage Island Farm, Kenneth Chooljian Vineyard and the Kearney Agricultural Center for use of their farms; the California Table Grape Commission, Lodi-Woodbridge Winegrape Commission, UC IPM Statewide Project, UC Sustainable Agriculture Research and Education program and the USDA National Research Initiative for providing funding; and Eric Davidian, Dean Greenwood, Ross Jones and Glenn Yokota for field and laboratory work.

\section{References}

Andow DA. 1991. Vegetational diversity and arthropod population response. Ann Rev Entomol 36:561-86.

Bugg RL, Waddington C. 1994. Using cover crops to manage arthropod pests of orchards: A review. Agricul, Ecosystems \& Environ 50:11-28.

Costello MJ, Daane KM. 1995. Spider (Araneae) species composition and seasonal abundance in San Joaquin Valley grape vineyards. Environ Entomol 24:823-31.
Costello MJ, Daane KM. 1997. Comparison of sampling methods used to estimate spider (Araneae) species abundance and composition in grape vineyards. Environ

\section{Entomol 26:142-9.}

Costello MJ, Daane KM. 1998a. Influence of ground covers on spider (Araneae) populations in a table grape vineyard. Ecol Entomol 23:33-40.

Costello MJ, Daane KM. 1998b. Abundance of spiders and insect predators on grape in Central California. J Arachnol (In Press).

Costello MJ, Daane KM. 1998c. Role of cover crops on vineyard arthropods. In: Ingels C, McGourty G, Christensen LP (eds.). Cover cropping in vineyards: a grower's handbook. University of California, DANR Publication. (In press).

Daane KM, Williams LE, Yokota GY, Steffan SA. 1995. Leafhoppers prefer vines with greater amounts of irrigation. Cal Ag 49(3):28-32

Kliewer WM, Wolpert JA, Lavec S. 1991 Integrated canopy management practices for optimizing vine microclimate, crop yield and quality of table and wine grapes. Bet Dagen. Israel.

Mayse MA, Striegler RK, O'Keefe WA, et al. 1995. Sustainable viticulture practices in the San Joaquin Valley of California. California Agriculture Technology Institute Bulletin, 951201

Pickett $\mathrm{CH}$, Wilson LT, González D, Flaherty DL. 1987. Biological control of the variegated leafhopper. Cal Ag-41(7):14-6.

Settle WH, Wilson LT, Flaherty DL, English-Loeb GM. 1986. The variegated leafhopper, an increasing pest of grapes. Cal $\mathrm{Ag} \mathrm{40(7):30-2}$

Triapitsyn SV. 1998. Anagrus (Hymenoptera: Mymaridae) egg parasitoids of Erythroneura spp. and other leafhoppers (Homoptera: Cicadellidae) in North American vineyards and orchards: a taxonomic review. Trans Am Entomol Soc 124:77-112.

Trichilo PJ, Wilson LT, Grimes, DW. 1990. Influence of irrigation management on the abundance of leafhoppers (Homoptera: Cicadellidae) on grapes. Environ Entomol 19:1803-9.

Wilson LT, Flaherty DL, Peacock WL. 1992a. Grape leafhopper. In: Flaherty DL, Christensen LP, Lanini WT, et al. (eds.). Grape pest management. University of California, DANR, Berkeley, CA. Publ. 3343. p 140-52.

Wilson LT, Barnes MM, Flaherty DL, et al. 1992b. Variegated grape leafhopper. In: Flaherty DL, Christensen LP, Lanini WT, et al. (eds.), Grape pest management. University of California, DANR, Berkeley, CA. Publ. 3343. p 202-13.

Wolpert JA, Phillips PA, McKenry MV et al. 1993. Berber orchardgrass tested as a cover crop in a commercial vineyard $\mathrm{Cal} \mathrm{Ag}$ 47(5): 23-5.

Zalom FG, Hanna R, Elmore C Christensen P. 1993. A cover crop for vineyard pest, weed and nutrition management. 1992-93 Ann. Report, Calif. Table Grape Comm., Fresno, CA. 